\title{
I-IV/P15
}

\section{Microcrystalline Silicon Thin Film Transistors Obtained by Hot-Wire CVD}

\author{
J. Puigdollers, ${ }^{* 1}$ D. Dosev ${ }^{2}$, A. Orpella ${ }^{1}$, C. Voz $^{3}$, D. Peiro ${ }^{3}$, \\ J. Bertomeu ${ }^{3}$, L.F. Marsal ${ }^{2}$, J. Pallares ${ }^{2}$, J. Andreu $^{3}$ and R. Alcubilla ${ }^{1}$ \\ ${ }^{1}$ Departament d'Enginyeria Electrònica. Universitat Politècnica de \\ Catalunya. Jordi Girona 1-3 Mòdul C4. 08034-Barcelona \\ ${ }^{2}$ Departament d'Enginyeria Electrònica. Universitat Rovira i Virgili. \\ ${ }^{3}$ Departament de Física Aplicada i Òptica. Universitat de Barcelona
}

\begin{abstract}
Polysilicon Thin Film Transistors (TFT) are of great interest in the field of large area microelectronics, especially because of their application as active elements in Flat Panel Displays. Different deposition techniques are in tough competition with the objective to obtain device-quality polysilicon thin films at low temperature. In this paper we present the preliminary results obtained with the fabrication of TFT deposited by Hot Wire Chemical Vapor Deposition (HWCVD). Some results concerned with the structural characterization of the material and electrical performance of the device are presented.
\end{abstract}

\section{Keywords}

1.- Microcrystalline silicon, 2.- Hot-Wire CVD, 3.- Thin Film Transistors.

\section{Introduction}

Thin Film Transistors are a prime interest topic because of their application in imagers, printers, and mainly as active elements in large active matrix liquid crystal displays (AMLCD)[1]. These devices are usually obtained using hydrogenated amorphous silicon $(\mathrm{a}-\mathrm{Si}: \mathrm{H})$ since this material can be easily deposited over large areas at low temperature allowing the use of cheap substrates. However, a-Si:H presents a low mobility and is unstable upon illumination and injection of charge. These aspects cause a-Si:H TFT to be slow devices, sensitive to light and heat. Among the different deposition techniques, Plasma Enhanced Chemical Vapour Deposition (PECVD) is the most used to obtain a-Si:H.

*Corresponding Author:

Tel: +34 934011002, Fax: +34934016756

E-mail: jpuigd@eel.upc.es 
The use of polycrystalline silicon (poly-Si) solves some of the problems previously cited. Polycrystalline silicon does not suffer from metastability and has better mobilities, that translate to display technology with a higher speed, inherent stability, brighter and higher resolution. These advantages are limited by the high processing temperature needed to obtain the poly-Si. For these reasons, there is a lot of research in order to obtain thin film material with properties that combine the advantage of the a-Si:H tecnology (large area deposition and low temperature) with the good electronic properties of polycrystalline silicon (stability and higher mobility). The use of microcrystalline silicon $(\mu \mathrm{c}-\mathrm{Si}: \mathrm{H})$ thin film material deposited at low temperature is a good alternative to substitute either for a-Si:H or for polycrystalline silicon. Among the different deposition techniques that are being investigated, the Hot Wire Chemical Vapour Deposition (HWCVD) has drawn a lot of attention because of its capability to obtain device-quality hydrogenated microcrystalline silicon $(\mu \mathrm{c}-\mathrm{Si}: \mathrm{H})$ at low temperature over large area $[2,3,4]$. In the HWCVD technique, gases are dissociated by the catalytic effect in a tungsten filament heated to high temperature $\left(\sim 1700^{\circ} \mathrm{C}\right)$. At first, this technique was basically used to obtain hydrogenated amorphous silicon, and its effectiveness for obtaining silicon thin film material with microcrystalline structure was not showed until recently. In this technique, the substrate temperature, process pressure and the gas composition (silane/hydrogen ratio) determine the structure (ranging from amorphous to microcrystalline) of the film. Recent experimental results reported by different groups confirm the potentiality of the HWCVD technique to obtain intrinsic and doped layers with grain sizes ranging from $0.3 \mu \mathrm{m}$ to $1 \mu \mathrm{m}$ at substrate temperatures as low as $200^{\circ} \mathrm{C}$. The good results obtained have encouraged some groups [5,6] to the fabrication of devices (solar cells and thin film transistors).

\section{Experimental}

The samples were deposited in a Hot Wire reactor as described elsewhere [7]. The reaction gases, a mixture of $\mathrm{SiH}_{4}$ and $\mathrm{H}_{2}$, were dissociated by a tungsten filament $(0.5 \mathrm{~mm}$ diameter $)$ heated to $1700^{\circ} \mathrm{C}$ and the substrates were placed $2 \mathrm{~cm}$ above the filament. The substrate temperature was measured by a thermocouple attached to the sample. Deposition parameters were: substrate temperature $280^{\circ} \mathrm{C}$, silane flux $4 \mathrm{sccm}$ and hydrogen flux $76 \mathrm{sccm}$, and the process pressure was $8 \cdot 10^{-2}$ mbar. Under these technological parameters the deposition rate was of $2 \AA / s$. Samples were structurally characterized by Raman Spectroscopy, X-Ray Difraction (XRD) and Transmission Electron Microscopy (TEM).

The TFT used in this work presented an inverted staggered structure which is the most commonly used configuration for flat panel applications. In this structure (figure 1) the gate dielectric is deposited before the $\mu \mathrm{c}-\mathrm{Si}: \mathrm{H}$ layer. A thermally oxidized n-type (100) silicon wafer with a

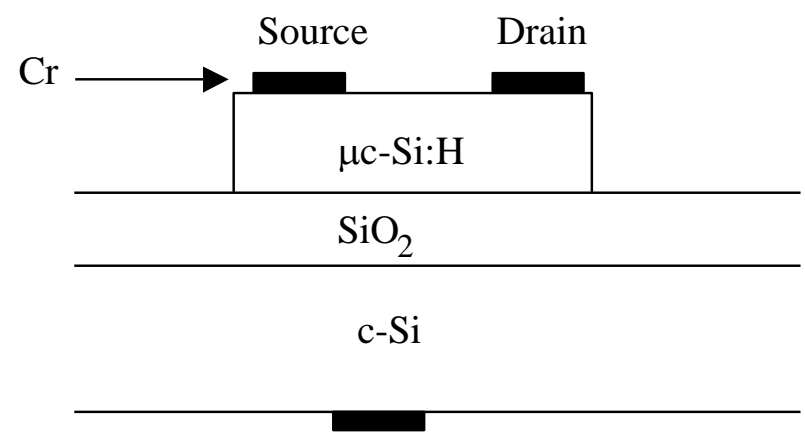

Cr Gate

Figure 1. Cross section of the inverted staggered Thin Film Transistor 
resistivity of $1-10 \Omega \cdot \mathrm{cm}$ was used as a substrate. The thickness of the oxide was $250 \mathrm{~nm}$. The $\mu \mathrm{c}-\mathrm{Si}: \mathrm{H}(250 \mathrm{~nm})$ was deposited at $280{ }^{\circ} \mathrm{C}$ by Hot Wire Chemical Vapour Deposition. Finally, a Chromium layer was thermally evaporated and the metallic contacts (drain and source) were delimited using photolitographic techniques. The channel width (W) was $137 \mu \mathrm{m}$ and the length (L) $55 \mu \mathrm{m}$, giving an aspect ratio for the device (i.e. gate width/length) of 2.5. It is known that the TFT characteristics are dominated by the first nanometers of the layer adjacent to the dielectric interface. For this reason, a pre-treatment of the silicon dioxide surface was done prior to the deposition of the undoped $\mu \mathrm{c}-\mathrm{Si}: \mathrm{H}$ film. This treatment consisted of exposing the substrate to the influence of atomic hydrogen atmosphere for 15 minutes in the Hot Wire CVD reactor. With this treatment we sought to eliminate surface defects and improve the adhesion of the $\mu \mathrm{c}-\mathrm{Si}: \mathrm{H}$ film on silicon dioxide. The electrical properties of the TFT were measured under dark conditions at ambient temperature $\left(25^{\circ} \mathrm{C}\right)$ using a semiconductor parameter analyzer (Hewlett Packard 41452B) and a programmable temperature controller (MMR Technologies, inc. K-20).

\section{Results}

\section{Material properties}

In this section we present the structural characteristics of the $\mu \mathrm{c}-\mathrm{Si}: \mathrm{H}$ film used for the fabrication of the TFT device. Figure 2 displays the Raman spectrum of a $\mu \mathrm{c}-\mathrm{Si}: \mathrm{H}$ film $(0.5 \mu \mathrm{m})$ deposited on Corning glass in the same run we deposited the TFT. The sharp peak at $520 \mathrm{~cm}^{-1}$ is due to the crystalline phase, whereas the broad peak centered about $480 \mathrm{~cm}^{-1}$ is related to the amorphous phase present in the layer. The ratio between the Raman intensities at $520 \mathrm{~cm}^{-1}$ and $480 \mathrm{~cm}^{-1}$ is usually used as a measure to determine the crystallinity of the film. In our sample the absence of the peak at $480 \mathrm{~cm}^{-1}$ together with the presence of a narrow peak at $520 \mathrm{~cm}^{-1}$ indicate the crystalline structure of the film. We have also measured the Raman spectrum with the beam incident through the glass, which allows to study the structural characteristics of the films at the first stages of the growth. The results were similar to those on the top surface, confirming the homogeneous structure of the film, and allowing us to ensure the microcrystalline structure of the TFT channel. The TO Raman peak of this layer presented a relative shift of around $3 \mathrm{~cm}^{-1}$ and a FWHM of $9 \mathrm{~cm}^{-1}$ which corresponds to

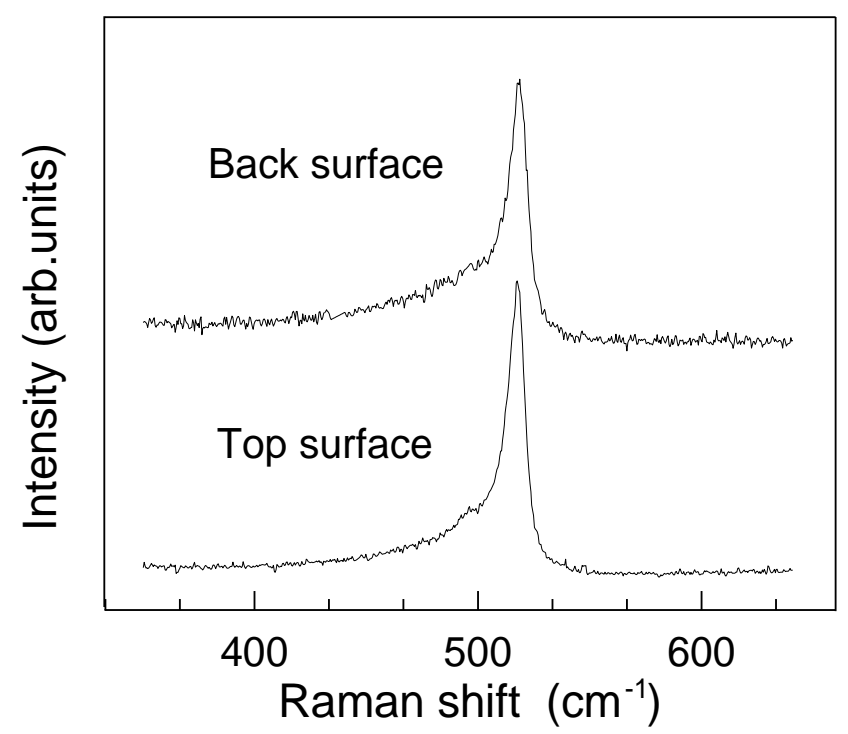

Figure 2. Raman spectrum of the microcrystalline silicon film. 


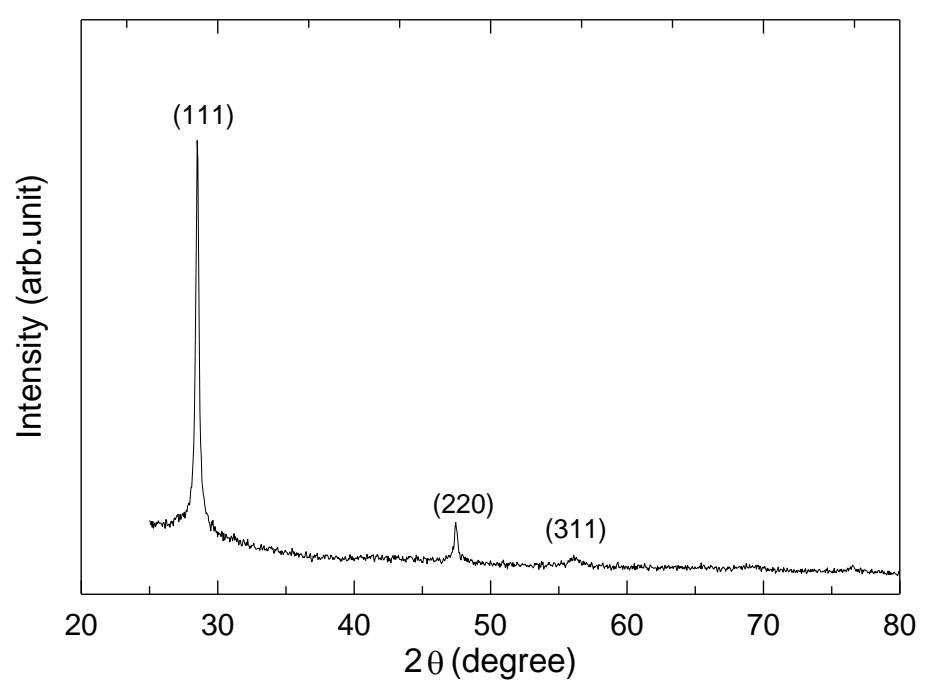

Figure 3. XRD spectrum of the microcrystalline film.

domain sizes of $8 \mathrm{~nm}$ by using the confinement model [8]. This fact has also been corroborated by TEM observations.

The crystallinity of the film was also observed by X-Ray diffraction. The $\theta / 2 \theta$ plot (figure 3 ) shows the main crystalline silicon difraction peaks. However the relative intensities of the (111), (220) and (311) peaks do not coincide with those obtained for powder c-Si, which indicate that crystallites are not randomly oriented in the film. The layer has a (111) preferential orientation, although some presence of the (220) is also observed.

The optoelectronic properties of the undoped $\mu \mathrm{c}-\mathrm{Si}: \mathrm{H}$ layer were: dark conductivity at room temperature: $2 \cdot 10^{-5} \Omega^{-1} \mathrm{~cm}^{-1}$; dark conductivity activation energy: $0.5 \mathrm{eV}$; density of defect states from the Photothermal Deflection Spectroscopy (PDS): $<10^{16} \mathrm{~cm}^{-3}$.

\section{Device characteristics}

In figure 4 the output characteristics $I_{D S}$ versus $V_{D S}$ at different $V_{G S}$ are shown. The output characteristics show small current crowding (a drain-source current which increases anomolously with increasing $V_{G}$, such that the output characteristics for different $V_{G}$ appear to crowd together) near the origin. This crowding indicates an appreciable influence of the contact resistance of the source and drain electrodes. This effect would be reduced by improving the contact resistance, for example by inserting an $\mathrm{n}^{+}$layer between the source/drain and the $\mu \mathrm{c}-\mathrm{Si}: \mathrm{H}$ layer. Good saturation of the output characteristics for all the gate voltages is also observed. The absence of the kink effect (a rapid rise of the $I_{D S}$ current above a high $V_{D S}$ applied) indicates that the electron injection at the contacts is very small.

In figure 5 the transfer characteristics of the transistor are presented. The application of a gatesource voltage $\left(\mathrm{V}_{\mathrm{GS}}\right)$ leads to an approximately exponential increase of the drain-source current $\left(\mathrm{I}_{\mathrm{DS}}\right)$, followed by a linear increase in current at higher voltages. Drain currents of $1 \mu \mathrm{A}$ can be obtained for gate voltages lower than $20 \mathrm{~V}$ even though the geometry of these devices is not optimized; in particular the aspect ratio is only 2.5. It is known that by increasing the aspect ratio of the device, the on-current and the transconductance would be improved. The relatively high value of the off-current (i.e. for negative gate voltage) is due to the hole current coming from the drain 


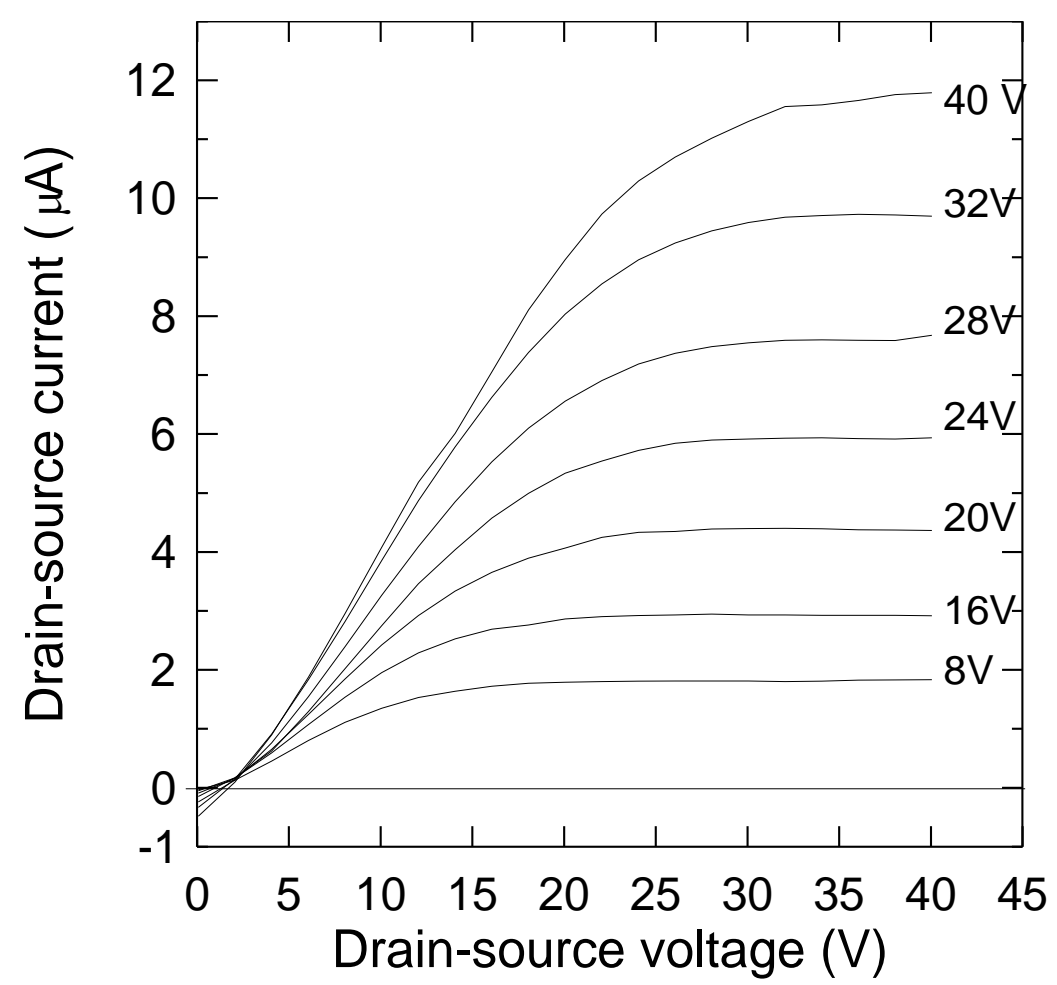

Figure 4. Output characteristics.

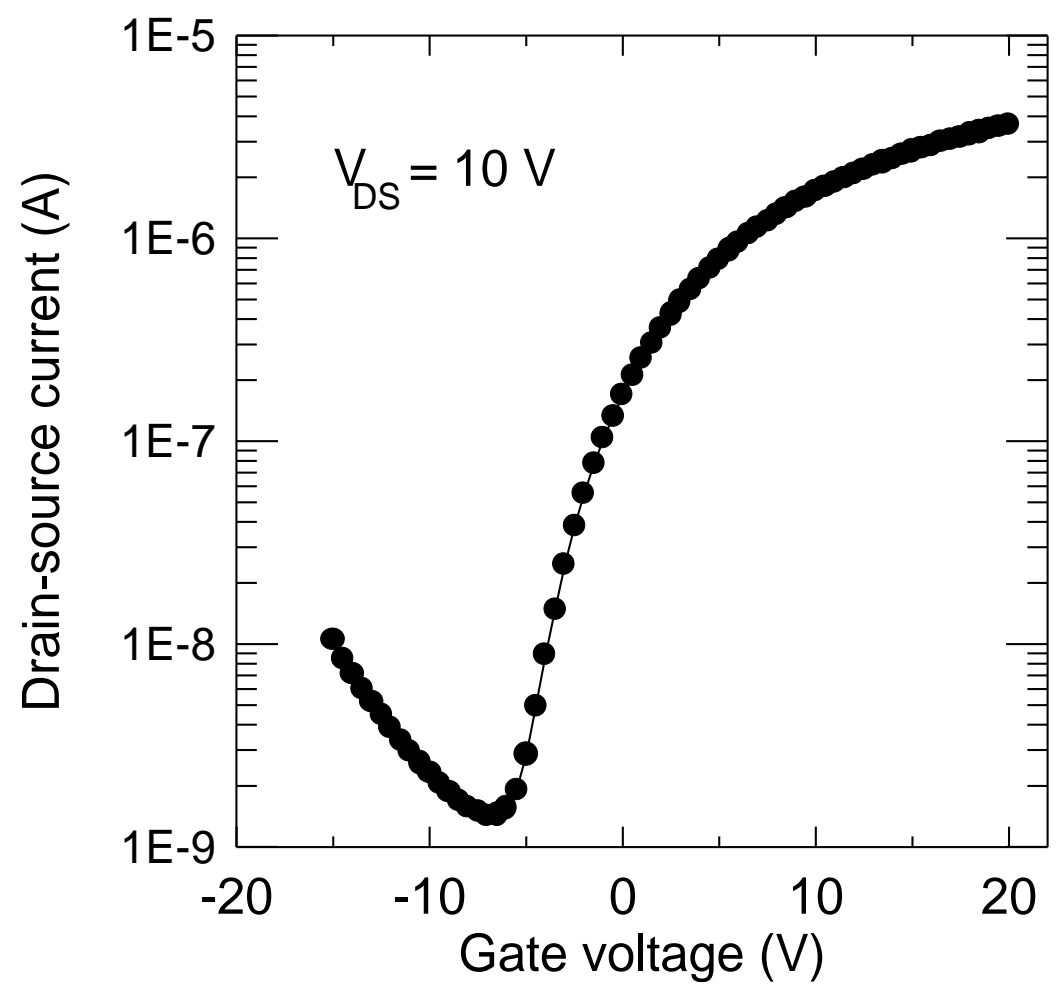

Figure 5. Transfer characteristics of the TFT 
and source contacts. This current can be reduced by incorporating $\mathrm{a} \mathrm{n}^{+}$doped layer between the $\mu \mathrm{c}-$ $\mathrm{Si}: \mathrm{H}$ layer and the metal contacts. The addition of this $\mathrm{n}^{+}$layer not only would reduce the offcurrent by blocking the hole current, but also would increase the value of on-current by reducing the contact resistance.

The field-effect mobility $\left(\mu_{\mathrm{s}}\right)$ and the threshold voltage $\left(\mathrm{V}_{\mathrm{t}}\right)$ can be obtained from the currentvoltage characteristics in the saturation regimen, i.e. $\mathrm{V}_{\mathrm{GS}}=\mathrm{V}_{\mathrm{DS}}$, where the drain-source current can be approximated by the following expression:

$$
I_{D S}=\frac{W}{L} \mu_{s} C_{o x} \frac{1}{2}\left(V_{G S}-V_{t}\right)^{2}
$$

where $\mathrm{W}$ and $\mathrm{L}$ are the gate width and length of the TFT respectively, and $\mathrm{C}_{\mathrm{ox}}$ is the capacitance of the insulator. By plotting the square root of $\mathrm{I}_{\mathrm{DS}} v s . \mathrm{V}_{\mathrm{G}}$ in the saturation regime (see figure 6) we have obtained a mobility value of $0.7 \mathrm{~cm}^{2} \cdot \mathrm{V}^{-1} \cdot \mathrm{s}^{-1}$ and a threshold voltage of approximately $0.3 \mathrm{~V}$.

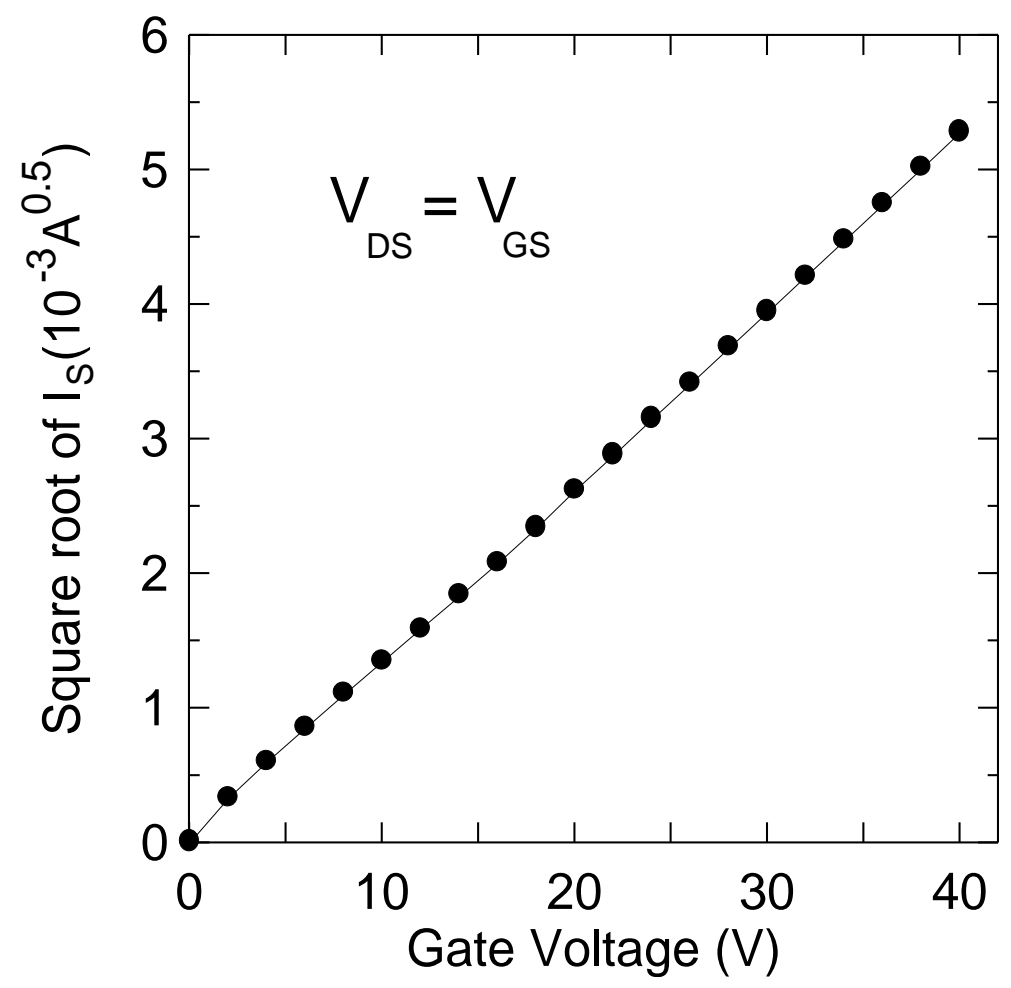

Figure 6. Transfer characteristics of the TFT

These values of mobility and threshold voltage are comparable to those reported in the literature [5], for TFT deposited by HWCVD with similar structure but incorporating an $\mathrm{n}^{+}$layer between the drain and source contacts and the $\mu \mathrm{c}-\mathrm{Si}: \mathrm{H}$ layer .

We have also measured the temperature dependence of the field-effect mobility. Figure 7 shows the mesured $\mu_{\mathrm{s}}$ as a function of temperature (from $0{ }^{\circ} \mathrm{C}$ to $80^{\circ} \mathrm{C}$ ). It is observed that $\mu_{\mathrm{s}}$ is thermally activated with an activation energy of $0.1 \mathrm{eV}$. This value of the activation energy corresponds to an effective charge trap density of about $10^{17} \mathrm{~cm}^{-3}$ (see for example Cap. 5 in ref. [9]), in concordance 


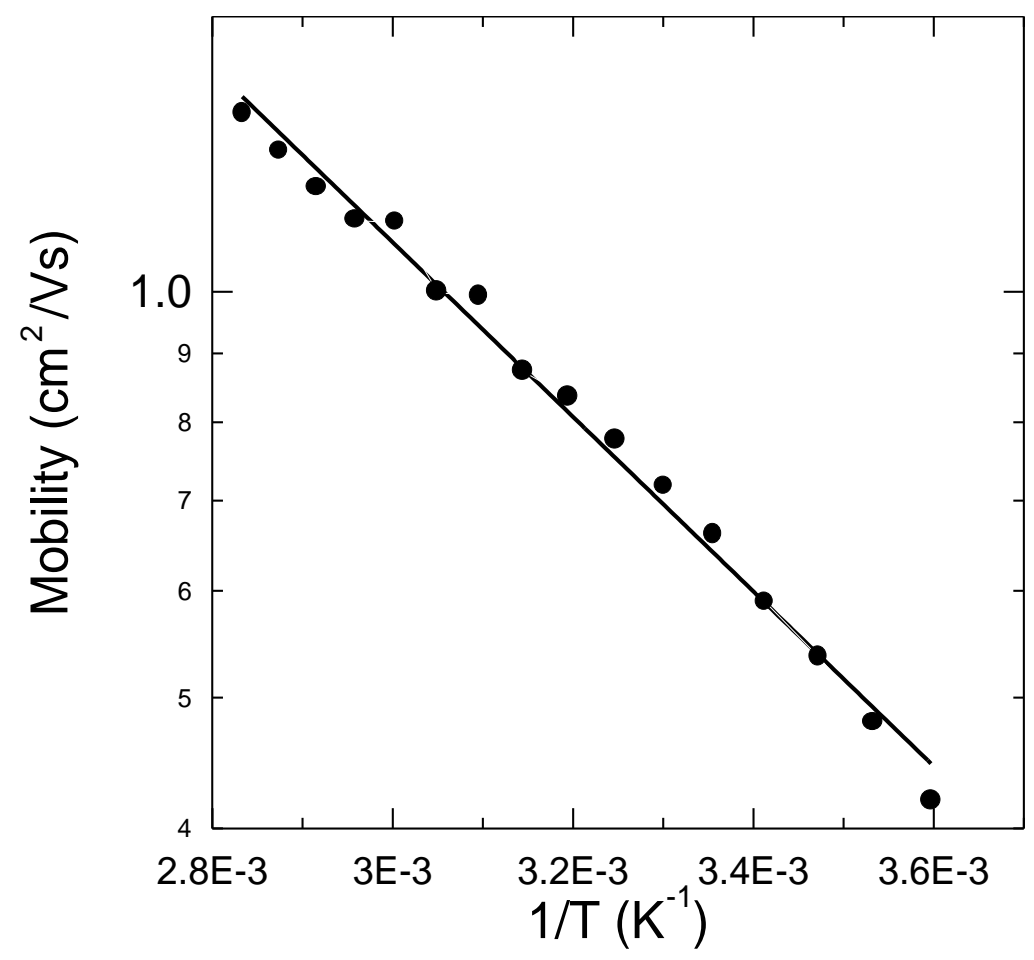

Figure 7. Dependence of the field-effect mobility with the temperature.

with standard Capacitance-Voltage measurements performed on a Schottky structure $\mathrm{ZnO} / \mu \mathrm{c}$ $\mathrm{Si}: \mathrm{H} / \mathrm{Cr}[10]$.

Our future work will focus on two aspects: The first one will be the improvement of the electrical characteristics of the TFTs by incorporating a $\mathrm{n}^{+}$doped layer between the electrodes and the $\mu \mathrm{c}-\mathrm{Si}: \mathrm{H}$ film. The second one will consist of the deposition of the $\mu \mathrm{c}-\mathrm{Si}: \mathrm{H}$ semiconductor on glass substrates using silicon nitride as a gate dielectric, that should allow us to study TFTs with the same boundary conditions to those of TFTs used as active elements in AMLCD.

\section{Conclusions}

In this paper we have presented the preliminary results obtained for TFTs using $\mu \mathrm{c}-\mathrm{Si}: \mathrm{H}$ deposited at low temperature by Hot Wire CVD. The TFTs had a staggered structure and silicon dioxide was used as a dielectric layer. Microcrystalline thin film material can be obtained by HWCVD at temperatures as low as $280^{\circ} \mathrm{C}$ with good structural and electronic properties. The transistors present satisfactory electrical performance with output characteristics with small crowding effect and good saturation level. A field-effect mobility of $0.7 \mathrm{~cm}^{2} / \mathrm{V} \cdot \mathrm{s}$ and a threshold voltage of approximately 0.3 $\mathrm{V}$ demonstrate the capability of the HWCVD technique to obtain device quality silicon thin film material. 


\section{Acknowledgements}

The authors would like to aknowledge the contribution of Dr. L. Fonseca from Centre Nacional de Microelectrònica for growing the silicon dioxide. Raman, XRD and TEM measurements were carried out at the Serveis Científico-Tècnics of the Universitat de Barcelona. This work was supported by the CICYT of the Spanish Government under programme TIC96-1058.

\section{References}

[1] Amorphous and Microcrystalline Semiconductor Devices, edited by J. Kanicki (Artech House, Norwood, MA, 1991).

[2] M. Ichikawa, J. Takeshita, A. Yamada, M. Konagai, "High Deposition rate of Polycrystalline Silicon Thin Films Prepared by Hot Wire Cell Method", Jpn. J. Appl. Phys. Vol. 38, pp. L24-L26, 1999.

[3] H. Matsumura, "Formation of Silicon-Based Thin Films Prepared by Catalytic Chemical Vapor Deposition (Cat-CVD) Method", Jpn. J. Appl. Phys. Vol. 37, pp. 3175-3187, 1998.

[4] J. Cifre, J. Bertomeu, J. Puigdollers, M.C. Polo, J. Andreu, A. Lloret, "Polycrystalline Silicon Films Obtained by Hot-Wire Chemical Vapour Deposition", Appl. Phys. A 59, pp. 645-651, 1994.

[5] H. Meiling, A.M. Brockhoff, J.K. Rath, R.E.I. Schropp, "Hydrogenated Amorphous Silicon and Polycrystalline Silicon TFTs by Hot-Wire CVD", J. Non-Cryst. Sol. 227-230, pp. 1202-1206, 1998.

[6] V. Chu, j. Jarego, H. Silva, M. Boucinha, P. Brogueira, J.P. Conde, "Amorphous Silicon ThinFilm Transistors with a Hot-Wire Active-Layer deposited at High Growth Rate", Mat. Res. Soc. Symp. Proc. Vol. 467, pp. 905-910, 1997.

[7] D. Peiró, J. Bertomeu, C. Voz, G. Robin, J. Andreu, "Doping Efficiencies of Microcrystalline Silicon Obtained at Low Temperature by Hot-Wire Chemical Vapour Deposition", $2^{\text {nd }}$ World Conference and Exhibition on Photovoltaic Solar Energy Conversion. Repport EUR 18656 EN. Joint Research Centre. European Commision (1998) 2294-2297.

[8] P.M. Fauchet, I.H. Campbell, "Raman Spectroscopy of Low-dimensional Semiconductors", Crit. Rev. Sol. State Mat. Sci. 14, S79, 1988.

[9] T. Kamins, "Polycrystalline Silicon for Integrated Circuit Applications", ed. Kluwer Academic Publishers, 1988.

[10] C. Voz, D. Peiró, M. Fontrodona, D. Soler, J. Bertomeu, J. Andreu, "Microdoping Compensation of Microcrystalline Silicon Obtained by Hot-Wire Chemical Vapor Deposition", to be sent to Solar Energy Materials and Solar Cells. 